\title{
Chapter 3 \\ Joachim Lompscher and His Activity \\ Theory Approach Focusing \\ on the Concept of Learning Activity \\ and How It Influences Contemporary \\ Research in Germany
}

\author{
Regina Bruder and Oliver Schmitt
}

\subsection{Introduction}

The concept of activity is a psychological construct that connects man and his development to culture and society. This concept was shaped substantially by Vygotsky, Leontiev, and Luria and developed further in the German-speaking countries by Lompscher ${ }^{1}$ in particular. The activity theory, which follows this line of tradition, has often been assigned to social constructivist approaches (Giest and Lompscher 2006, p. 231; Woolfolk 2008, p. 421). Lompscher elaborated the concept of learning activity with regard to teaching practice and applied it to several

\footnotetext{
${ }^{1}$ Joachim Lompscher (1932-2005) is considered the "founder of educational psychology and of the psychology of learning activities in the GDR" (Rückriem and Giest 2006, p. 161, translated). Focal points of his academic work were the development of mental abilities, the training of learning activities, the cultural-historical school of Soviet psychology and the associated activity theory, and aspects of its development in the history of psychology. He studied psychology and education in Moscow and defended his doctoral thesis in Leningrad in 1958 on the subject "On the understanding of children of some spatial relationships" (translated). He subsequently worked at the Humboldt University of Berlin, moved to the German Central Institute of Psychology (DZPI) in 1962, and from 1966 was there in a leading position for practical teaching projects and issues in the mental development of children. He habilitated in Leipzig in 1970 and was subsequently appointed Professor of Educational Psychology at the Academy of Educational Sciences (APW) in Berlin. After German reunification in 1991, he worked at the Institute of Learning and Teaching Research at the University of Potsdam (For an obituary and bibliography, see Rückriem and Giest 2006).
}

\author{
R. Bruder $(\bowtie) \cdot$ O. Schmitt \\ Fachbereich Mathematik, Technical University Darmstadt, Schlossgartenstr. 7, \\ D-64289 Darmstadt, Hessen, Germany \\ e-mail: bruder@mathematik.tu-darmstadt.de \\ O. Schmitt \\ e-mail: oschmitt@mathematik.tu-darmstadt.de
}

(C) The Author(s) 2016

A. Bikner-Ahsbahs et al., Theories in and of Mathematics Education,

ICME-13 Topical Surveys, DOI 10.1007/978-3-319-42589-4_3 
subjects. The core objective of teaching is the training of learning activity, which is aimed at acquiring social knowledge and competence and requires specific means under specially arranged conditions. The concepts of learning tasks and orientation bases of learning actions are closely linked to the concept of learning activity. These conceptual bases are briefly presented in Chap. 2, whilst Chap. 3 refers to current applications of the activity theory in German-speaking research on teaching methodologies.

Contemporary activity theory became an interdisciplinary discourse mainly through the works of Engeström in the field of the emerging labour research. This line of research sees itself as an "intervention approach to the study of changes and learning processes at work, in technology and organisations" (Engeström 2008, p. 17, translated) and is based on the tradition of the cultural-historical activity theory. In his theory and intervention methodology, Engeström dealt with the solution to practical social issues and, among other things, also provided valuable impulses for the development of teaching staff in schools (Engeström 2005).

Increased attention is also given to activity theory in international discussions on teaching methodologies (see Mason and Johnston-Wilder 2004), with the German-speaking countries contributing concepts such as describing the use of digital tools in mathematics classes (see Ladel and Kortenkamp 2013).

\subsection{Conceptual Bases}

The central concept of activity has been described as "the specifically human form of activity, of interaction with the world in which man changes it and himself at the same time" (Giest and Lompscher 2006, p. 27, translated). Activity takes place through the conscious influence of a subject on an object in order to shape the latter in accordance with the motive of the activity. To this end, such actions (material or spiritual) are performed within one activity line that each time realises certain sub-goals through to the ultimate product of the activity. At the same time, the concept of operation serves to further distinguish another form of subordinate activity that differs from actions by the fact that operations result from concrete conditions for action and pass in an automated manner without conscious control or goal formation. These represent shortened actions.

In the course of their lives, humans, in their confrontations with the world, develop various forms of activity, such as play, work, or learning activities that feature different characteristics in each case. For schools and for didactic research, the concept of learning activity has been of key importance. There, learning activity has been understood "as the activity aimed specifically at acquiring social knowledge and competence (learning topics) for which purpose specific means (learning resources) under specially arranged conditions have to be adopted." (Giest and Lompscher 2006, p. 67, translated). According to Lompscher (1985), three essential subjective requirements must be met on the part of the learners to achieve a learning activity: 
- Concrete learning goals as individual mental anticipation of the desired results and of the activity aimed at such results.

- Learning motives as the motivational basis to perform certain activities.

- Learning activities as:

Relatively closed and identifiable steps, structured in terms of time and logic, in the course of the learning activity, which realise a concrete learning goal, are driven by certain learning motives and are executed, according to concrete learning conditions, by the use of external and internalised learning resources in a specific sequence of sub-actions each time. (p. 46, translated)

The aim of school education has been without doubt to stimulate and promote learning activities in the learner. For instance, for mathematics classes, tasks have traditionally been perceived as a key creative resource of the teacher. Within the framework of the activity theory, suitable learning tasks have been understood as requests to perform learning actions (Bruder 2010, p. 115). There, a distinction has been made between the requirements imposed by teachers in relation to the learning topics and the learning tasks assigned by the learners to themselves. When planning classes, attention should be paid to allow as much scope as possible "for the construction of individually suitable learning tasks" (Bruder 2008, p. 52, translated).

Learning actions implemented in learning activity can be of a very different nature. According to Lompscher, various categories of learning actions can be distinguished depending on the learning task dominating in a given learning situation. These include, for instance (Lompscher 1985):

- observing objects, processes and situations according to pre-set or independently developed criteria;

- collecting, compiling, and processing data or materials for specific purposes and under certain aspects;

- performing actions of a practical or concrete nature to manufacture a product or to change it with regard to certain quality and effectiveness parameters;

- presenting circumstances orally and in writing for specific purposes whilst considering certain conditions;...

- assessing and evaluating third-party or own performance or behaviour or a given event with regard to certain measures of value;

- proving or refuting views in an arguing manner on the basis of certain positions, findings or facts;

- solving problems of various structures and contents; and

- practising certain actions (p. 48 , translated).

These actions can be developed and recalled by learners in different ways (level of awareness and acquisition of an action). "One action can be performed at a level of relatively unfocused trial and error behaviour, whereas another one would proceed as a target-oriented search, adequate as per circumstances, with purposeful implementation of correlations recognised" (Lompscher 1985, p. 49, translated). 
This issue can be described in a more differentiated way through an analysis of the structure of learning actions. Within an action, three different parts have been distinguished: the orientation part, the performance part, and the control part (see Giest and Lompscher 2006, p. 197). In the orientation part, an orientation basis is formed as a provisional idea of a task (Galperin 1967, p. 376) on the basis of which the action is eventually performed and the result of which is controlled with regard to previous goals. The concept of orientation basis was developed by the Soviet educationalist Galperin and extensively appreciated by didactic research in the GDR, particularly by Lompscher. According to Lompscher, the following issues in relation to requirements and the learning topic are relevant in the formation of the orientation basis (Giest and Lompscher 2006):

- What (requirement structure, sequence of sub-actions)

- How (examination conditions, resources, methods, quality of the action)

- Why (reason for the action, its inner connections)

- What for (classification of the action in overall connections, possible consequences, etc.) (p. 192, translated).

A distinction has basically been made between three different types of orientation (Giest and Lompscher 2006, pp. 192ff) — here reflecting the designations by Bruder (2005, p. 243):

- Trial orientation (Probierorientierung) designates an incomplete orientation basis entailing an action after trial and error; awareness of the procedure is very limited only and a transfer is hardly possible on that basis.

- In pattern orientation (Musterorientierung), some aspects and conditions of a requirement are recognised and associated with an example (pattern) already solved; the orientation basis is complete but transferable to a delimited area only, as no comprehension of the entire requirement class takes place.

- Field orientation (Feldorientierung) designates a complete general orientation basis resulting from an independent analysis of the requirements of a given field of knowledge or thematic field, which therefore allows for good transferability of the knowledge and actions acquired to new requirements.

If the requirement is, for instance, about solving a linear equation, learners with trial orientation would rather proceed by making transformations in an unsystematic manner or perhaps guess the figures and possibly even be successful. With pattern orientation they could also try to trace a systematic approach on the basis of an example already known to them, which would possibly allow for limited transferability to similar examples. Finally, in case of a developed field orientation, general strategies could be used, such as a separation between variable and constant terms on both sides of the equation.

By means of learning actions, depending on the arrangement of the learning environment, different orientation bases can be promoted in learners. Within the scope of practising processes during introductions to solving quadratic equations, the examining operation as to which type of equation is actually involved will 
become less important. Learners will be aware of what the current issue is about. Schematic practising can therefore only bring assurance and automatisms in processing algorithmic step sequences. Still, this does not lead to a transferable acquisition of the object. So, for instance, when solving a given quadratic equation within the scope of an aptitude test for vocational training, it will first have to be recognised that indeed such a type of equation is involved. If such an assignment is successful, the solution methods available will possibly be activated (development of example-based orientation). Such a task will only make higher demands on orientation building if the relevant equation type is still unknown or as part of mixed exercises at a later date.

If solution methods (graphic solutions, calculation formulae) can be activated at least at the level of example-based orientation, the relevant task can mostly be solved, except for some calculation or presentation errors. If such recognition of the equation type is not successful, various search processes are initiated, often with incorrect schema assignments, or the attempt at solution is discontinued altogether. In such a situation, intuitive reference is made to the basic concepts available and even to everyday experiences in the form of empirical generalisations. This, according to Nitsch (2015), would also explain, for instance, the differing stability of error patterns, whilst competing example-based orientations are available, partly incorrect or inadequate, which can be recalled depending on the context.

The approach of orientation bases yields important conclusions when considering a long-term development of fundamental mathematical competencies, such as in mathematical argumentation. To achieve high quality in the training for learning action "proving or refuting in an arguing manner" in mathematics classes, knowledge relevant to action is required. In particular, such knowledge is necessary as to which arguments are admissible in mathematics and which methods of conclusion are possible in order to be able to develop a field orientation for a processing strategy in relation to a given proof-related task. If such background knowledge is lacking, any transfer of this procedure, even with simple justifications (are all rectangles trapezia, too?), to other mathematical contents, such as proofs of divisibility, will hardly succeed. Instead, attempts are made to develop further example-based orientation within the new scope. Here, in schematic practising processes, the procedure is just transferred from one task to an analogous task, without awareness of what the procedure actually consists of. Such reflection processes with the building of knowledge are part of the training for a given learning action (in stages) and a necessary prerequisite for developing field orientation with the corresponding demands. If the demands remain at the level of analogous tasks, there will be no need to develop orientations of a higher quality and thus to advance the respective learning action.

In order to stimulate an orientation as far-reaching as possible at an early stage of the learning process, i.e., the formation of a learning goal, a teaching strategy, going back to Davydov (1990), of the rise from the abstract to the concrete has to be developed. As a first interim result in the learning process, a so-called starting abstract (Ausgangsabstraktum) is developed together with the learners, which maps, relates, and anchors the essential characteristics of the learning topic and 
offers a framework for the continuation of the teaching process. The starting abstract is thus "the result of learning activity already and as such the starting point for rising to the concrete" when further working with concrete contents (Giest and Lompscher 2006, p. 222, translated). Due to the heterogeneity of the learners, the tasks assigned by the teacher, which first have to be transformed into individual learning tasks, should allow for orientation at different levels to give the learners a chance to reach the individual zone of the next development stage in terms of Wygotskij (Bruder 2005, p. 243).

An approach to learning phenomena based on the activity theory by Lompscher includes the following aspects (Lompscher 1990):

- the quality of the learning motives and goals at the activity level, which determine the concrete purpose and process of the learning actions;

- the interrelations between the activity and action (and also operation) levels, for instance, with regard to contradictions between activity motivation and concrete situational action motives; and

- the cognitive, metacognitive, emotional, motivational and volitive regulation bases, and the process structure of learning actions and learning outcomes (in terms of psychological changes).

- This and other questions can be worked on at different analysis levels, starting (1) with the most general components, relations and determinants of the macrostructure of the activity, via (2) an analysis of concrete classes of learning activities, such as learning from texts or solving problems with certain, although different, categories of learners, through to 3. the microanalysis of elementary components and processes based on performance of the action (p. 1f, translated).

\subsection{Exemplary Applications of the Activity Theory}

Applications of the activity theory in German-speaking countries primarily refer to the analysis and formation of learning activities in connection with their corresponding knowledge, abilities, and skills. In parallel, various types of competence modelling on the basis of concepts of the activity theory have been performed or operationalised for diagnosis.

A consistent implementation of the activity theory according to Lompscher and in connection with Davydov was presented in the works on a theory of learning tasks by Dietz and associates (reported in Brückner 2008).

Mann (1990) explained learning how to read and write and do arithmetic on the basis of the activity theory and demonstrates how successful this approach has been for the development of learning surroundings even for people with intellectual disabilities.

The idea of the cognitive process as a unity of analysis and synthesis, going back to Rubinstein (1973), was expanded by Lompscher to describe the structure of mental abilities with the components mental operations and process qualities. The 
presentation by Lompscher (1975, p. 46) on the model interrelations between analytical and synthetic operations in mental activities was taken up by Bruder and Brückner (1989). According to this approach, identifying and realising mathematical contents can be described as elementary actions on the basis of defined mental operations. Empirical studies provide preliminary indications of evidence that these two elementary actions can be distinguished and also of basic actions of a more complex construction, such as describing and justifying each time in relation to given mathematical concepts, connections, or processes (see Nitsch 2015). Such a hierarchical approach to describing learning actions results in a heuristic construction for learning and test tasks (see the general approach to the task theory in Bruder 2003) which has already proven its worth in theoretical competence modelling. These action hierarchies are currently being used in a project aimed at describing the requirements for the central school-leaving examinations in Austria in a four-stage competence structure model for action dimensions in operating, modelling, and arguing (see Siller et al. 2015). Such a theoretical background was also used for the construction of items within the scope of the project HEUREKO on the empirical clarification of competence structures in a specific mathematical context, notably the changes of representation of functional relationships (see Nitsch et al. 2015).

Boehm (2013) used basic positions of the activity theory to establish curricular objectives for mathematical modelling at Secondary Level I. The theoretical framework for the analysis of modelling activities that he elaborated allows for a differentiated model description of the action elements in mathematical modelling. This also includes the successful involvement and clarification of problem-solving activities in modelling.

Mathematical problem-solving competence can be interpreted, from an activity theory angle, as variously pronounced mental agility where mental agility represents a marked process quality of thinking [see the construct of process qualities in Lompscher (1976)]. According to Lompscher (1972, p. 36), content and the progress of learning actions are decisive for the result. Bruder's (2000) operating principle in acquiring problem-solving competence was that through the acquisition of knowledge about heuristic strategies and principles, insufficient mental agility can partly be compensated. This approach was transferred to a teaching concept about learning how to solve problems in four stages building on each other, and the corresponding effects at student level have been empirically proven (Bruder and Collet 2009; Collet and Bruder 2008).

Nitsch (2015) investigated typical difficulties of learning in changes of representation of functional relationships and interpreted these as incomplete orientation bases. Existing error patterns could be described as inadequate patterns. In this way, and in connection with the concept of basic ideas (Vom Hofe 1995), a tentative explanation is provided about mechanisms to activate certain mathematical (error-) ideas.

In terms of orientation bases, there was a discussion in the 1970 s both in the GDR and in a Western response by critical psychology about whether another type going beyond the field orientation should be added to the previously mentioned 
orientation types. The intention of this orientation type was to describe the creative handling of open issues that did not already have any known or generally recognised solutions at hand. Taking up this discussion and providing a response to the teaching strategy of the rise from the abstract to the concrete, Schmitt (2013) developed a concept to promote reflective knowledge (Fischer 2001; Skovsmose 1989 ) in mathematics classes in a targeted manner.

Feldt (2013) uses concepts of the activity theory as a background to conceptualise minimum standards. The activity theory offers opportunities to operationalise learning goals through its central concepts of learning action and learning task but also through the construct of the acquisition quality of knowledge (see Pippig 1985) in connection with the orientation bases of the learning actions. In particular, the quality feature of availability of knowledge, which has been highly relevant in conceptualising minimum standards, is being discussed with a view to a possible gradation in the style of Sill and Sikora (2007) and is being further refined with regard to such gradation.

Open Access This chapter is distributed under the terms of the Creative Commons Attribution 4.0 International License (http://creativecommons.org/licenses/by/4.0/), which permits use, duplication, adaptation, distribution and reproduction in any medium or format, as long as you give appropriate credit to the original author(s) and the source, a link is provided to the Creative Commons license and any changes made are indicated.

The images or other third party material in this chapter are included in the work's Creative Commons license, unless indicated otherwise in the credit line; if such material is not included in the work's Creative Commons license and the respective action is not permitted by statutory regulation, users will need to obtain permission from the license holder to duplicate, adapt or reproduce the material. 